\title{
Performance of carbon fiber reinforced rubber composite armour against shaped charge jet penetration
}

\author{
Lian-yong Yue ${ }^{1}$, Wei $\mathrm{Li}^{2}$, Xu-dong $\mathrm{Zu}^{3, a}$, Zheng-xiang Huang ${ }^{3}$, Zhen-yu Gao ${ }^{3}$ \\ 1 Shandong Special Industry Group Co.,Ltd., Zibo 255201, China \\ 2 Xi'an aerospace propulsion institute, Xi'an 710100, China \\ ${ }^{3}$ School of Mechanical Engineering, Nanjing University of Science and Technology, Nanjing 210094, China
}

\begin{abstract}
Natural rubber is reinforced with carbon fiber; the protective performances of the carbonfiber reinforced rubber composite armour to shaped charge jet have been studied based on the depth of penetration experiments. The craters on the witness blocks, the nature rubber based composite plates' deformation and the Scanning Electron Microscopy for the hybrid fiber reinforced rubber plate also is analyzed. The results showed that the composite armour can affect the stability of the jet and made part of the jet fracture. The carbon fiber reinforced rubber composite armour has good defence ablity especially when the nature rubber plate hybrid $15 \%$ volume percentage carbonfiber and the obliquity angle is $68^{\circ}$. The hybrid fiber reinforced rubber composite armour can be used as a new kind of light protective armour.
\end{abstract}

\section{Introduction}

Shaped charge jet (SCJ) has an excellent penetration performance and can damage armoured targets effectively as one of the most important against armour weapons. It is an issue of common concern how to protect the armoured vehicles to reduce damage by the SCJ. According to the study, the bulging armour can disturb the stability of the SCJ and has excellent resistance to penetration performance, so it has been widely used in the protective field of armoured vehicles, ships and aerospace. The fiber reinforced composite materials as sandwich materials are widely used in the bulging armour. Fiber reinforced rubber base composite materials are materials with doped fiber by a certain percentage in rubber to obtain specific material properties. Carbon fiber is one kind of reinforcing fibers commonly used.

Current literature indicates that rubber base composite armour can disturb the SCJ stability, make the SCJ fracture and broken as a kind of additional armour. The description of the mechanisms of these bulging systems was first proposed by Gov [1]. Yaziv compared rubber composite and explosive reactive armours, highlighting the former as superior in terms of safety and environmental effects [2]. The study further described the process of interaction of rubber composite armour with a SCJ, but did not provide the theoretical model. Rosenberg studied the resistance capability of sandwich composite armours with different sandwich materials through twodimensional (2D) simulation and considered material strength, stress modulus, and density to be important factors for the resistance of a composite armour to a SCJ [3]. A layer of rubber, which will gasify, or even explode, is regarded as an inert explosive. A mechanism for the interaction based on the theory of Kelvin-Helmholtz instabilities was discussed by Helte et al. [4]. The process of rubber composite armour against SCJ penetration was divided into four parts based on jet deformation that occurred when the SCJ penetrated the rubber composite armour. Results on the interference speed interval, interference frequency, and surplus penetration capability of the SCJ with the rubber composite armour were derived based on the stress wave and Kelvin-Helmholtz instability theory. The effects of rubber layer thickness and obliquity of the armour for the composite armour anti-Shaped charge jet penetration were studied through theoretical, X-ray, and depth of penetration experiments by X.D. $\mathrm{Zu}$ et al [5]. The protection ability of woven fabric reinforced rubber composite armour subjected to shape charge jet was studied by X. Jia et al through experiments [6]. Hybridization with one or more fiber type in the composite material provides positive or negative effect on the mechanical properties of the composite material [7-10].So the protective performance of the composite armour in which the sandwich plate is carbonfiber reinforced composite material plate should study by experiments.

The research of the protective performance about the carbonfiber reinforced rubber composite armour which is one kind of important protective armours, against SCJ is important. In the case of carbonfiber reinforced rubber composite armour, however the mechanism and

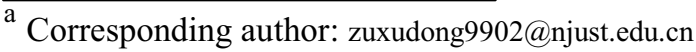


simulation are significantly more complex because of the interaction of the carbonfiber reinforced rubber composite armour and the SCJ. Hence, in this paper, we study the protective performance of the carbonfiber reinforced rubber composite armour in which the rubber base is hybrid with carbonfiber at two obliquity $\left(60^{\circ}, 68^{\circ}\right)$ through depth of penetration (DOP) experiments. The tip velocities of the SCJ after penetrating the composite were measured in the DOP experiments. The effect of the carbonfiber for the composite armour was studied by the tip velocities of the SCJ, the DOP, and the protection factors.

\section{Shaped charge and carbonfiber reinforced rubber composite armour condition}

\section{$2.156 \mathrm{~mm}$ standard shaped charge}

The standard shaped charge was used in this study for several reasons, such as the increasing the universality of the study; simplifying the calculation of the protection, cost, and protection thickness coefficients; and considering that the standard shaped charge is often used in studies. The standard shaped charge (Figure 1) has the following characteristics: shaped charge copper liner with $0.8 \mathrm{~mm}$ thickness and $56 \mathrm{~mm}$ diameter, explosive quality of $203 \mathrm{~g}$ without a conical charge shell cover. In order to measure the standard shaped charge jet parameters the DOP experiments was set as Figure 2, with the standoff $330 \mathrm{~mm}$, and the velocity sensors set at the top and the bottom of the standoff cylinder to measure the time of the shaped chare jet tip through the standoff, and the $8 \#$ flash detonator was used to detonate the SCJ. The results of the experiments are shown in the Table 1.

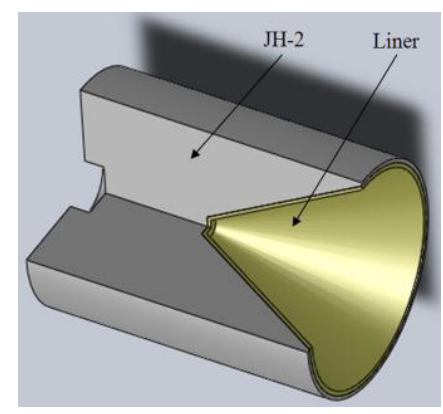

Figure 1. Photograph of the standard shaped with a diameter of $56 \mathrm{~mm}$.

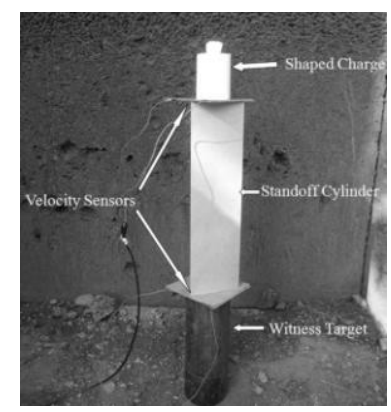

Figure 2. DOP experimental setup with the velocity sensors to measure the velocity of the shaped charge jet tip.

Table 1. Results of shaped charge performance experiment.

\begin{tabular}{|c|c|c|c|c|}
\hline $\begin{array}{c}\mathbf{N} \\
\mathbf{o .}\end{array}$ & $\begin{array}{c}\text { Standof } \\
\mathbf{- f ( \mathbf { m m } )}\end{array}$ & $\begin{array}{c}\text { Time } \\
(\boldsymbol{\mu s})\end{array}$ & $\begin{array}{c}\text { Velocity of } \\
\text { jet tip (m/s) }\end{array}$ & $\begin{array}{c}\text { Depth of pene- } \\
\text { tration(mm) }\end{array}$ \\
\hline 1 & 330 & 51 & 6470 & 161 \\
\hline 2 & 330 & 51 & 6470 & 158 \\
\hline 3 & 330 & 51 & 6470 & 160 \\
\hline
\end{tabular}

The result shows the average depth of penetration to be $160 \mathrm{~mm}$ at the same standoff, with a relative error of approximately $5 \%$. The depth of $160 \mathrm{~mm}$ was regarded as the datum, which is aimed at the condition of SCJ penetration of the semi-infinite steel target. The SCJ has good consistency, and the inlet diameter was almost as same as the outlet diameter. In the DOP experiments the velocity of the shaped charge jet tip was $6470 \mathrm{~m} / \mathrm{s}$. The jet tip and tail velocities were measured using the multichannel X-ray system at the same time. The double flash $\mathrm{X}$-ray exposures of the shaped charge jet at $30 \mu$ s and 50 $\mu \mathrm{s}$ after initiation were shown in the figure 3 . The magnification of the X-ray exposures is 2.0. So the jet tip velocity was $6453 \mathrm{~m} / \mathrm{s}$ and that of the tail was $1179 \mathrm{~m} / \mathrm{s}$. Compared the velocity of the shaped charge jet tip obtained from the X-ray exposures with that measured from the DOP experiments, the relative error is not beyond $0.3 \%$.

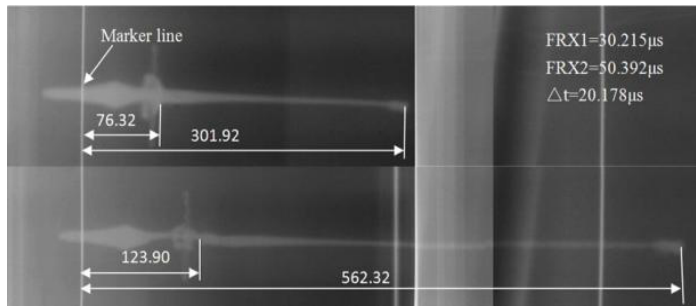

Figure 3. Double flash X-ray exposures of the shaped charge jet at 30 and 50us after initiation (all dimensions in $\mathrm{mm}$ ).

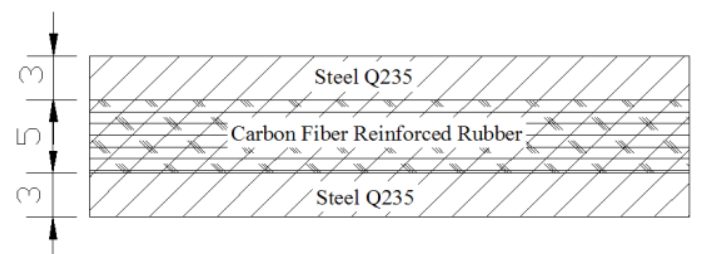

Figure 4. Schematic of the carbon fiber reinforced rubber composite armour.

\subsection{Carbonfiber reinforced rubber composite armour construction}


Table 2. Summary of rubber parameters.

\begin{tabular}{|c|c|c|c|c|c|c|}
\hline $\begin{array}{c}\text { Ma } \\
\text { teri } \\
\text { al }\end{array}$ & $\begin{array}{c}\mathbf{\rho ( g /} \\
\left.\mathbf{c m}^{3}\right)\end{array}$ & $\begin{array}{c}\text { Thick } \\
\text { ness } \\
\mathbf{( m m )}\end{array}$ & $\begin{array}{c}\text { Shore } \\
\text { hardn } \\
\text { ess }\end{array}$ & $\begin{array}{c}\text { Tensil } \\
\mathbf{e} \\
\text { streng } \\
\text { th(M } \\
\mathbf{P a})\end{array}$ & $\begin{array}{c}\text { Stretch } \\
\text { modulu } \\
\mathbf{s ( G P a )}\end{array}$ & $\begin{array}{c}\text { Elongat } \\
\text { ion } \\
\text { failure( } \\
\mathbf{\%})\end{array}$ \\
\hline $\begin{array}{c}\mathrm{Ru} \\
\text { bbe } \\
\text { r }\end{array}$ & 1.3 & -- & 75 & 20 & -- & 400 \\
\hline $\begin{array}{c}\text { Car } \\
\text { bon }\end{array}$ & 1.90 & 0.17 & -- & 2.6 & 400 & 1.5 \\
\hline $\begin{array}{c}\text { Q2 } \\
35\end{array}$ & 7.85 & -- & -- & 375 & -- & 2.6 \\
\hline
\end{tabular}

The carbonfiber reinforced rubber composite armour configuration comprised the following layers: Q235 steel, carbon fiber reinforced rubber material, Q235 steel. The thickness of the Q235 steel plates and rubber base material sandwich plate were $3 \mathrm{~mm}$ and $5 \mathrm{~mm}$. The carbonfiber reinforced rubber composite armour had area geometry of $300 \mathrm{~mm} \times 150 \mathrm{~mm}$. The Q235 steel was sandblasted and a pre-mium grade adhesive was used to bond steel plates and hybrid fiber reinforced rubber plate. The parameters of the rubber, carbon fiber and Q235 steel are shown in the Table2.

\section{Experiments}

\subsection{DOP experiment setup}

To investigate the protective capability of the carbonfiber reinforced rubber composite armour against shaped charge, the DOP method was used in the experiment. A schematic diagram of the sides of the DOP experiment configuration is shown in figure 5. Given the velocity sensors after the carbonfiber reinforced rubber composite armour and before the witness target along the shaped charge jet direction of movement, the distance between the two velocity sensors $250 \mathrm{~mm}$ (the real distance can be measured before experiment) and the velocity of the shaped charge jet can be calculated. At the $330 \mathrm{~mm}$ distance standoff, the $45 \#$ steel witness targets were set to measure the depth of the residual penetration capability.

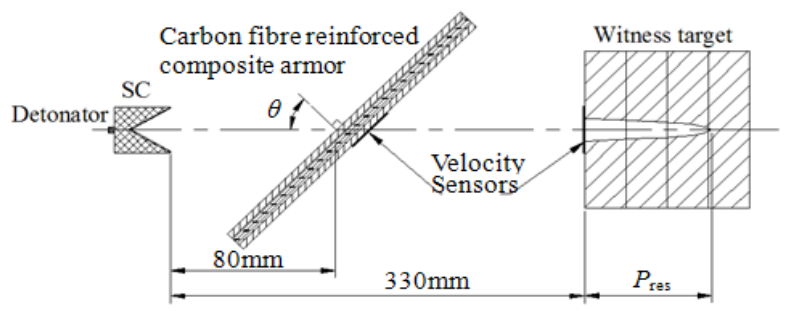

Figure 5. Schematic diagram of the experimental setup.

\subsection{Experiments scheme}

Two kind of volume percentage of carbonfiber in the nature rubber, and two kind of obliquity of the composite were chose in the paper. The detailed importations were showed in the Table 3.

Table 3. The detailed importations of the carbonfiber in the nature rubber of the experiments.

\begin{tabular}{|c|c|c|c|c|c|c|}
\hline Case & $\mathbf{1}$ & $\mathbf{2}$ & $\mathbf{3}$ & $\mathbf{4}$ & $\mathbf{5}$ & $\mathbf{6}$ \\
\hline Fiber type & \multicolumn{2}{|c|}{ Carbon fiber } \\
\hline $\begin{array}{c}\text { Volume } \\
\text { percentage }\end{array}$ & \multicolumn{2}{|c|}{7} & \multicolumn{2}{|c|}{7} & \multicolumn{2}{|c|}{15} \\
\hline $\begin{array}{c}\text { Obliquity } \\
\theta / \%\end{array}$ & 60 & 68 & 60 & 68 & 60 & 68 \\
\hline
\end{tabular}

\section{Result and dicussion}

\subsection{Efficiency factors}

The carbonfiber reinforced rubber composite armour was placed at a certain distance upon the main armour as additional armour to improve the protection performance. The surplus depth of penetration cannot evaluate the protection performance of the carbonfiber reinforced rubber composite armour directly when the condition of the armour changed. Space protection coefficient $\left(E_{s}\right)$, quality protection coefficient $\left(\mathrm{E}_{\mathrm{m}}\right)$, providing information to an armour designer for armoured vehicle protection without needing to provide details on the structure and mechanism of the armour systems. Efficiency is always indicated in a standard or reference value.

The space protection coefficient, quality protection coefficient were calculated to describe the protective performance of the armour systems. The space protection coefficient is the ratio between the spaces of the tested armour with that of the reference armour when they have the same protection ability. The quality protection coefficient is the ratio between the qualities of the tested armour with that of the reference armour when they have the same protection ability.

$$
\begin{aligned}
& \mathrm{E}_{\mathrm{m}}=\frac{P_{s t} P_{0}}{\sum_{\mathrm{i}=1}^{3} \frac{P_{\mathrm{p}} \mathrm{h}_{\mathrm{i}}}{\cos \mathrm{\theta}}+P_{s t} P_{\mathrm{res}}} \\
& \mathrm{E}_{\mathrm{m}}=\frac{P_{\mathrm{st}} P_{0}}{\sum_{\mathrm{i}=1}^{3} \frac{P_{\mathrm{i}} \mathrm{h}_{\mathrm{i}}}{\cos \theta}+P_{s t} P_{\mathrm{res}}}
\end{aligned}
$$

Where, $\rho_{\text {st }}$ denotes the density of steel, $\rho_{1}, \rho_{3}$ denote the densities of the cover plates, $\rho_{2}$ denotes the density of the sandwich material, $h_{1}$ and $h_{3}$ denote the thickness of the cover plates respectively, $h_{2}$ denotes the thickness of the sandwich material, $p_{0}$ denotes the depth of penetration of the standard SCJ with the standoff $330 \mathrm{~mm}, p_{\text {res }}$ denotes the surplus depth of penetration of the SCJ after the jet penetrated the composite armour, $\theta$ denotes the angle between the normal direction of the plates and the axial direction of the SCJ.

\subsection{Results of DOP experiments}

The jet tip average velocities after the jet penetrated the carbonfiber reinforced rubber composite armour were 
measured, and depth of penetration, the diameter of the jet penetrated the witness blocks were acquired through the depth of penetration experiments. The detailed information of the results was showed in table 4 .

Where, pres denotes the depth of penetration of the escape jet penetrated the witness blocks, $\Delta \mathrm{L}$ denotes the true distance from the back plate of the composite armour to the surface of the witness blocks, $\Delta \mathrm{t}$ denotes the time from the sensor on the back plate of the composite armour to the sensor which was set on the surface of the witness blocks, $V_{j}$ denotes the jet tip average velocities after the jet penetrated the hybrid fiber reinforced rubber composite armour, $\mathrm{D}_{\mathrm{r}}$ denotes the diameter of the jet penetrated the witness blocks. All the dates given in the tables are the average date of three tests. The velocity of the case 2 was not acquired in the table, because the experiments of case 2 were not done together with others.

Table 4. The results of the DOP experiments.

\begin{tabular}{|c|c|c|c|c|c|c|c|}
\hline $\begin{array}{c}\mathbf{C a} \\
\mathbf{s e}\end{array}$ & $\begin{array}{c}\mathbf{P}_{\mathbf{r e s}} \\
(\mathbf{m} \\
\mathbf{m})\end{array}$ & $\begin{array}{c}\Delta \mathbf{L} \\
(\mathbf{m m})\end{array}$ & $\begin{array}{c}\Delta \mathbf{t} \\
(\boldsymbol{\mu s})\end{array}$ & $\begin{array}{c}\mathbf{V}_{\mathbf{j}} \\
(\mathbf{m} / \mathbf{s})\end{array}$ & $\begin{array}{c}\mathbf{D}_{\mathbf{r}} \\
\mathbf{( m}\end{array}$ & $\mathbf{E}_{\mathbf{m}}$ & $\mathbf{E}_{\mathbf{s}}$ \\
\hline 1 & 80 & 228 & 4.3 & 5302 & 23 & 1.72 & 1.99 \\
\hline 2 & 69 & 220.6 & -- & -- & 24 & 1.85 & 1.75 \\
\hline 3 & 117 & 228 & 3.8 & 6000 & 24 & 1.23 & 3.66 \\
\hline 4 & 75 & 220.6 & 4.2 & 5252 & 24 & 1.73 & 1.87 \\
\hline 5 & 101 & 228 & 3.9 & 5846 & 23 & 1.40 & 2.68 \\
\hline 6 & 66 & 220.6 & 4.0 & 5515 & 15 & 1.91 & 1.69 \\
\hline
\end{tabular}

\subsection{Results of the craters on the witness blocks}

The middle part of the escape jet will fracture and scatter after the jet penetrated the carbonfiber reinforced rubber composite armour. When the escape jet penetrated the witness blocks, there will be many craters on the surface of the witness blocks. The condition of the escape jet fracture and scatter will be shown by the diameter of the penetrated hole and craters on the surface of the witness blocks. The results of the penetrated hole and the craters penetrated by the escape jet were showed in figure 6 .

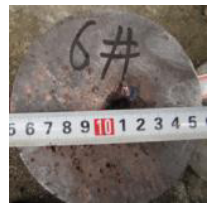

Case 1

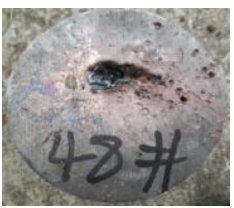

Case4

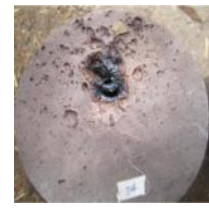

Case2

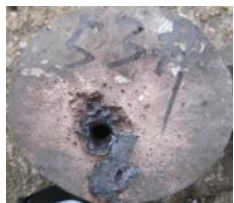

Case5

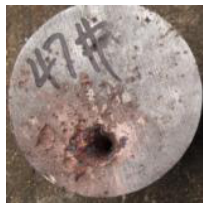

Case 3

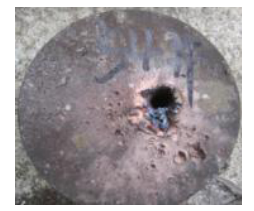

Case6
Figure 6. Schematic diagram of the experimental setup.
The figure 6 shows that the composite armour can disturb the stability of the shaped charge jet, and can made part of the escape jet fragment and fracture. When the carbonfiber reinforced nature rubber as the sandwich plate the craters on the surface of the witness blocks less than the craters on the witness blocks while the nature rubber as the sandwich plate of the composite armour, but the depth of the craters more deep for the carbonfiber reinforce rubber composite armour than the nature rubber composite armour. The amount of the craters are larger when the obliquity of the composite at $68^{\circ}$ than the obliquity of the composite at $60^{\circ}$.

\section{Conclusion}

A series of DOP test have been carried out to evaluate the effects of nature rubber composite and carbonfiber reinforced rubber composite armour against $\Phi 56 \mathrm{~mm}$ shaped charge jet penetrated when the obliquity at $60^{\circ}$ and $68^{\circ}$. Carbon fabric was used as the hybrid reinforcement respectively. Based on these findings the following conclusions could be drawn:

The carbonfiber reinforced the breaking strength of rubber base material and increased the absorptive capability to shock wave.

The composite armour has better protection performance with obliquity of $68^{\circ}$ than that of $60^{\circ}$.

The carbonfiber reinforced rubber composite armour has better protection performance when the carbonfiber volume percentage is $15 \%$ than the carbonfiber volume percentage is $7 \%$.

The carbonfiber reinforced rubber composite armour has good defence ablity especially when the nature rubber plate hybrid $15 \%$ volume percentage carbonfiber. The hybrid fiber reinforced rubber composite armour can be used as a new kind of light protective armour.

\section{References}

1. N. Gov, Y. Kivity, and D. Yaziv, On the interaction of a shaped-charge jet with a rubber balled metallic cassette [C]. 13th Int. Symp. On Ballistics, Stockholm,Vol I, 95-99 (1992)

2. D. Yaziv, S. Friling, N. Gov. The interaction of inert cassettes with shaped charge jets [C]. 15th Int. Symp. on Ballistics, Jerusalem, Vol I, 461-467 (1995)

3. Z. Rosenberg, E. Dekel. A parametric study of the bulging process in passive cassettes with 2D numerical simulations [C]. Int. J. Impact Engineering, 21(4), 297-305 (1998)

4. A. Helte, E. Lidén. The role of Kelvin-Helmholtz instabilities on shaped charge jet interaction with reactive armours plates [C]. 25th International Symposium on Ballistics, Beijing, Vol II, 1547-1553 (2010)

5. X.D. Zu, Z.X. Huang, X. Jia. Study on Rubber Composite Armour Anti-Shaped Charge Jet Penetration[J]. Propellants, Explosives, Pyrotechnics, Online, DOI:10.1002/prep.201200172, (2013)

6. Xin Jia, Zheng-xiang Huang, Xu-dong Zu, Xiao-hui $\mathrm{Gu}$, Chuan-sheng Zhu, Zhong-wen Zhang. 
Experimental study on the performance of woven fabric rubber compo site armoursubjected to shape d char ge jet impact[J]. International Journal of Impact Engineering. 57, 134 -144 (2013)

7. M. Idicula, N.R. Neelakantan, Z. Oommen, et al. A study of the mechanical properties of randomly oriented short banana and sisal hybrid fiber reinforced polyester composites[J]. Journal of applied polymer science, 96(5), 1699-1709 (2005)

8. M. Grujicic, B. Pandurangan, D.C. Angstadt, et al. Ballistic-performance optimization of a hybrid carbon-nanotube/E-glass reinforced poly-vinyl-esterepoxy-matrix composite armour[J]. Journal of materials science, 42(14), 5347-5359 (2007)

9. M. Grujicic, W.C. Bell, L.L. Thompson, et al. Ballistic-protection performance of carbon-nanotubedoped poly-vinyl-ester-epoxy matrix composite armour reinforced with E-glass fibermats[J]. Materials Science and Engineering: A, 479(1), 10-22 (2008)

10. M. Jacob, S. Thomas, K.T. Varughese. Mechanical properties of sisal/oil palm hybrid fiber reinforced natural rubber composites[J]. Composites Science and Technology, 64(7), 955-965 (2004) 